\title{
Factor V levels and risk of venous thrombosis: The MEGA case- control study
}

\author{
Inge M. Rietveld MSc ${ }^{1,2}$ | Mettine H. A. Bos PhD ${ }^{1,2}$ | Willem. M. Lijfering PhD ${ }^{1,2,3}$ | \\ Ruifang Li-Gao MSc ${ }^{3}$ (D) | Frits R. Rosendaal PhD ${ }^{1,3}$ | Pieter H. Reitsma PhD ${ }^{1,2}$ | \\ Suzanne C. Cannegieter $\mathrm{PhD}^{2,3}$
}

${ }^{1}$ Einthoven Laboratory for Experimental Vascular Medicine, Leiden University Medical Center, Leiden, The Netherlands

${ }^{2}$ Department of Thrombosis and Haemostasis, Leiden University Medical Center, Leiden, The Netherlands

${ }^{3}$ Department of Clinical Epidemiology, Leiden University Medical Center, Leiden, The Netherlands

\section{Correspondence}

Dr. Suzanne C. Cannegieter, Department of Clinical Epidemiology, Leiden University Medical Center, Leiden, the Netherlands.

Email: s.c.cannegieter@lumc.nl

\section{Funding Information}

The Multiple Environmental and Genetic Assessment of Risk Factors for Venous Thrombosis was supported by grant NHS 98.113 from the Netherlands Heart Foundation, grant RUL99/1992 from the Dutch Cancer Foundation, and grant 912-03-033 I 2003 from the Netherlands Organization for Scientific Research. The funding agencies had no role in the design and conduct of the study; collection, management, analysis, and interpretation of the data; and preparation, review or approval of the manuscript. Technology Foundation STW (project: E-coagulation) supported the work of I.M.R. and W.M.L.; The Center for Translational Molecular Medicine (CTMM; project: Innovative Coagulation Diagnostics (INCOAG)) supported the work of M.H.A.B.

\begin{abstract}
Background: Blood coagulation levels are associated with risk of venous thrombosis (VT). The role of factor (F)V is ambiguous since it plays a dual role in coagulation: it has a procoagulant role when it serves as a cofactor for the activation of thrombin and it has an anticoagulant role by enhancing the inactivation of activated FVIII.

Objectives: To elucidate the association of FV levels with risk of VT.

Patients/Methods: We analyzed FV antigen levels in 2377 patients with VT and 2943 controls from the MEGA study. FV levels were categorized according using the 1st, 2.5th, 5th, 10th, 25th, 50th, 75th, 90th, and 95th percentiles of FV levels in controls as cut-off points. Odds ratios (ORs) were estimated using logistic regression models and adjusted for age and sex, liver disease, FVIII levels, FV Leiden, and TFPI. Results: The risk estimates were U-shaped with increased ORs for the lowest $(<0.57$ $\mathrm{U} / \mathrm{dL}$ ) levels (OR 1.46; 95\% $\mathrm{Cl}$ 0.87-2.43) as well as the highest (>1.22 U/dL) (OR 1.86; $95 \% \mathrm{Cl} 1.46-2.37$ ) levels as compared with the reference group (25th-50th percentile). FVIII adjustment led to attenuation of the OR for high FV levels (OR 1.14; 95\% $\mathrm{Cl} 0.88-1.48$ ), with little change for low FV levels (OR 1.68; 95\% $\mathrm{Cl} 0.97-2.91)$. Other adjustments had limited effects.

Conclusions: We found high FV levels to be associated with increased risk for VT, which was explained by concurrently raised FVIII levels. For low levels of factor V, the increased risk for VT could not be explained by the mechanisms we explored.
\end{abstract}

\section{KEYWORDS}

case-control studies, coagulation factors, Factor V, Factor VIII, venous thrombosis

\section{Essentials}

- No clear association between FV concentration and venous thrombosis (VT) has been described yet.

- This association was studied in a large case-control study on VT (MEGA-study).

- Both high and low FV levels were associated with VT risk.

- Association with high FV levels was dependent on FVIII levels, that with low FV levels was not. 


\section{INTRODUCTION}

Venous thrombosis (VT) is a common disease, affecting 1-4 in 1000 people annually. ${ }^{1,2}$ Over the past two decades, it has become apparent that VT is associated with increased levels of procoagulant coagulation factor levels. ${ }^{3-8}$ Of these procoagulant factors, factor VIII (FVIII), a cofactor in the conversion of factor X (FX) to activated FX, is associated with the strongest increased risk for $\mathrm{VT}{ }^{8}{ }^{8}$ Another wellknown risk factor for $V T$ is the Leiden variant of factor $V(F V)$, which is less sensitive to inhibition by activated protein C (APC) due to the Arg506GIn mutation. ${ }^{9}$ However, there have been conflicting reports on the association between VT and FV levels. Factor $\mathrm{V}$ is a cofactor in the FX-dependent conversion of prothrombin to thrombin, the latter being the key regulatory enzyme of coagulation. Full FV deficiency is incompatible with life, while individuals with low plasma FV levels or residual FV activity in platelets only suffer from mild to moderately severe bleeding episodes. ${ }^{10,11}$ In addition to its procoagulant function, FV has also been reported to function as an anticoagulant by enhancing the APC-mediated inactivation of FVIII. ${ }^{12,13}$ This dual role complicates predictions on the role of FV in VT occurrence. Where one study reported an association of low FV levels and $\mathrm{VT},{ }^{14}$ we previously demonstrated an association with high FV levels. ${ }^{15}$ Neither study looked into both high and low FV levels.

Here, we aimed to elucidate the association of FV levels with VT by using data from the Multiple Environmental and Genetic Assessment of risk factors for VT (MEGA) case-control study, considering both high and low FV levels. The large size of this study provides the opportunity to obtain precise estimates and study multiple subgroups. Since FVIII levels were previously found to have a strong association with VT and considering that the association between high levels of other coagulation factors was mainly dependent on FVIII, (Rietveld et al. 2018) we further studied the association between FV and FVIII. Furthermore, we explored the causal relations in more detail by adjustment for FV Leiden, for liver disease, as low FV levels are a marker for liver failure ${ }^{16}$ and for tissue factor pathway inhibitor (TFPI), which can bind FV ${ }^{17,18}$ and is associated with VT risk. ${ }^{19,20}$

\section{2 | METHODS}

The MEGA-study is a large, population-based case-control study into risk factors for $\mathrm{VT}$. In brief, consecutive patients with a first objectively confirmed episode of deep venous thrombosis or pulmonary embolism were included. ${ }^{21}$ Blood samples were provided by 2377 patients and 2939 controls ( 1480 partners of patients and 1459 subjects from the general population reached by random-digit dialling [RDD] controls). In patients the blood was drawn approximately three months after discontinuation of oral anticoagulant therapy; in patients who were still on anticoagulant therapy one year after the event, blood was drawn during anticoagulant therapy.

All assays were performed by laboratory technicians who were unaware of the case-control status of the samples. The FV levels were determined employing an in-house developed sandwich enzyme-linked immunosorbent assay (ELISA) using two monoclonal antibodies recognizing the light chain ( $\mathrm{V}-6)$ or the heavy chain (V-39) of $\mathrm{FV}^{22}$ Therefore, this assay was specific for single chain FV, including FV-short. FVIII levels were determined using a commercially available ELISA. Total TFPI activity in plasma was measured using the Actichrome TFPI activity assay (Sekisui Diagnostics, Stamford, $\mathrm{CT})$.

Odds ratios (ORs) and their 95\% confidence intervals (95\% Cls) were calculated as an estimate of the relative risk of VT for factor V levels and adjusted for age and sex using logistic regression. Linear regression of FV and FVIII levels was performed to study the association between these two factors. The risk estimates were adjusted for FVIII levels to evaluate whether the observed relation was mediated or confounded by FVIII levels. Furthermore, the risk estimates were adjusted for FV Leiden, liver disease (self-reported in questionnaire) and TFPI activity levels. Measurements in RDD subjects and partners of patients were pooled since median values of FV levels were similar in RDD and partner controls (Table 1). Cut-off points in factor levels were set at the 1st, 2.5th, 5th 10th, 25th, 50th, 75th, 90th and 95th percentiles of antigen levels in the control population and entered into the model as categorical data. Additionally, a subanalysis was performed for unprovoked VT, which was defined as VT not related with recent surgery, trauma, plaster cast, hospitalization, being bedridden at home, cancer at or 5 years prior to event, oral contraceptive use, pregnancy, or long-haul travel. Of note, the large size of the MEGA study allowed us to look into the extremes of the FV range, for the low levels even below the first percentage. However, this was not possible for the high levels since the used assay had a cut-off at $125 \mathrm{U} / \mathrm{dL}$. Diluted samples could not be extrapolated linearly to match the main dataset. Therefore, we cannot distinguish between high (>95th percentile) and very high (>99th percentile).

Various genetic factors have been known to be associated with FV levels. Here we confirmed this for FV Leiden ${ }^{15}$ and for two SNPs in the FV gene (rs6033 proxy by rs1800595 and rs9332701). ${ }^{23}$

We attempted to replicate the findings of the MEGA study in a smaller case-control study: the LETS (Leiden Thrombophilia Study). In brief, 474 cases and 474 controls with a first deep venous thrombosis provided a blood sample. Individuals suffering from cancer were excluded and blood samples were obtained after at least three months' withdrawal of anticoagulant therapy. FV levels were determined with an in-house developed sandwich ELISA employing monoclonal antibodies recognizing the FV light chain (V-6 and V9). ${ }^{15}$ Factor VIII levels were determined with a one-stage clotting assay using factor FVIII-deficient plasma. ${ }^{8}$ The ORs and $95 \% \mathrm{Cls}$ for the association between FV and VT were calculated and adjusted for age, sex, FVIII, and liver disease. To ensure robust group sizes the cut-off points in factor levels were set at the 2.5th, 5th 10th, 25th, 50th, 75th, 90th and 95th percentiles of antigen levels in the control population and entered into the model as categorical data.

The MEGA study and the LETS were approved by the Ethics Committee of the Leiden University Medical Center, and written 


\begin{tabular}{|c|c|c|c|c|}
\hline & $\begin{array}{l}\text { Patients } \\
2377\end{array}$ & $\begin{array}{l}\text { RDD controls } \\
1459\end{array}$ & $\begin{array}{l}\text { Partner controls } \\
1480\end{array}$ & $\begin{array}{l}\text { RDD and } \\
\text { partner } \\
\text { controls } \\
2939\end{array}$ \\
\hline Male & $1085(46)$ & $674(46)$ & 719 (49) & $1393(47)$ \\
\hline Age at enrollment & $49(38-58)$ & $48(38-58)$ & $51(41-58)$ & $50(38-58)$ \\
\hline $\begin{array}{l}\text { FV Leiden (hetero/ } \\
\text { homozygote) }\end{array}$ & $360 / 16(15 / 0.7)$ & $74 / 2(5 / 0.1)$ & $64 / 4(4.3 / 0.3)$ & $138 / 6(4.7 / 0.2)$ \\
\hline Liver disease $^{b}$ & $15(0.6)$ & $6(0.4)$ & $5(0.3)$ & $11(0.4)$ \\
\hline \multicolumn{5}{|l|}{ Coagulation factors } \\
\hline Factor $\mathrm{V}: \mathrm{Ag}, \mathrm{U} / \mathrm{dL}$ & $94(82-106)$ & $91(80-104)$ & $92(81-103)$ & $92(81-104)$ \\
\hline $\begin{array}{l}\text { Factor VIII:Ag, } \\
\text { IU/dL }\end{array}$ & $147(116-186)$ & $107(86-136)$ & $110(86-141)$ & 109 (86-139) \\
\hline
\end{tabular}

TABLE 1 Clinical characteristics of the MEGA study

Continous variables denoted as medians (IQR), categorical data as counts (\%). RDD denotes random digit dialing. ${ }^{a} 1$ value missing ${ }^{b} 57$ values missing.

informed consent was obtained from all participants. The investigation has been conducted according to the principles expressed in the Declaration of Helsinki. Statistical analyses were performed with SPSS for Windows, release 22.0 (SPSS Inc., Chicago, IL, USA).

\section{3 | RESULTS}

Table 1 shows the characteristics of the study population. The median FV level was $94 \mathrm{U} / \mathrm{dL}$ in patients and $92 \mathrm{U} / \mathrm{dL}$ in controls. There was no difference in the median levels of the partner and RDD controls ( $92 \mathrm{U} / \mathrm{dL}$ vs. $91 \mathrm{U} / \mathrm{dL}$ ). The risk estimates distribution of FV levels followed a U-shaped curve (Figure 1), with elevated risks for both high (>95th percentile; >122 U/dL; OR 1.86; $95 \%$ $\mathrm{Cl} 1.46-2.37)$ and low (<1st percentile; <57 U/dL; OR 1.46; $95 \%$ $\mathrm{Cl}$ 0.87-2.43) levels of FV (Table 2). Adjustment for liver disease had no effect on the risk estimates. In accordance with previous research, ${ }^{8}$ median levels of FVIII were markedly higher in patients than in controls. We found an association between FV and FVIII levels. For each increase of $1 \mathrm{IU} / \mathrm{dL}$ in FVIII in the controls, FV levels increased with $0.44 \mathrm{U} / \mathrm{dL}(95 \% \mathrm{Cl} 0.34-0.53)$, with an $\mathrm{R}^{2}$ of
2.6\% (data not shown). When the risk analysis was adjusted for FVIII levels, the ORs were almost reduced to unity for elevated levels of FV (OR 1.14; 95\% Cl 0.88-1.48). However, the elevated risk estimates observed for low FV levels slightly increased, with an OR of 1.68 (95\% Cl 0.97-2.91) for the lowest levels of FV (<1st percentile) and an $\mathrm{OR}$ of $1.65(95 \% \mathrm{Cl} 1.05-2.60)$ for the group between the 1 st and 2.5 th percentile $(57-63 \mathrm{U} / \mathrm{dL}$ ). The $\mathrm{U}$-shape appearance of the ORs disappeared at the upper end following FVIII adjustments but the increased risk remained for the lower FV levels (Figure 1). The adjustment of FV levels for total TFPI had no effect on the risk estimates (Table 2), ruling out a role for total TFPI.

Since FV Leiden is a common and strong risk factor for VT, we determined the levels of FV in controls with a normal genotype and for individuals homo- or heterozygous for this mutation. FV levels were lowest in noncarriers of FV Leiden, slightly higher in individuals heterozygous for FV Leiden (mean difference of $6.2 \mathrm{U} / \mathrm{dL}$ ), and highest for homozygous FV Leiden carriers (mean difference of 12.2 $\mathrm{U} / \mathrm{dL}$, Table 3). Therefore, we adjusted the FV levels for FV Leiden to control for possible confounding by FV Leiden. This had limited effect on the risk estimates (Table 2). Furthermore, we observed that

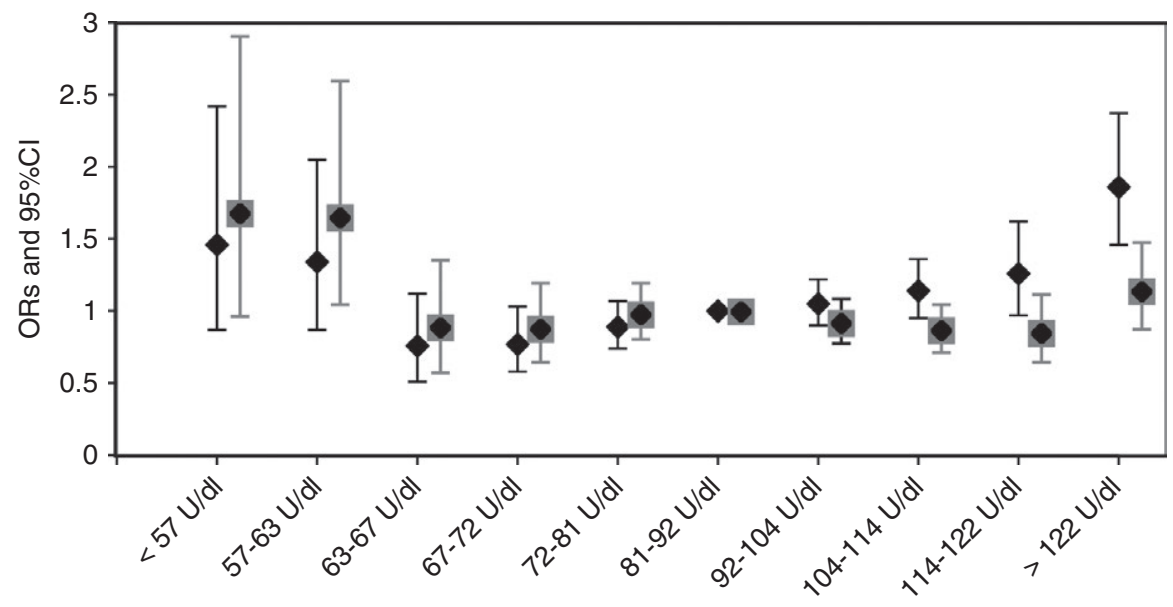

FIGURE 1 Overview of the ORs and 95\% $\mathrm{Cls}$ adjusted for age and sex (black) and adjusted for age, sex, and FVIII (grey) of the association between FV levels and VT in the MEGA study 

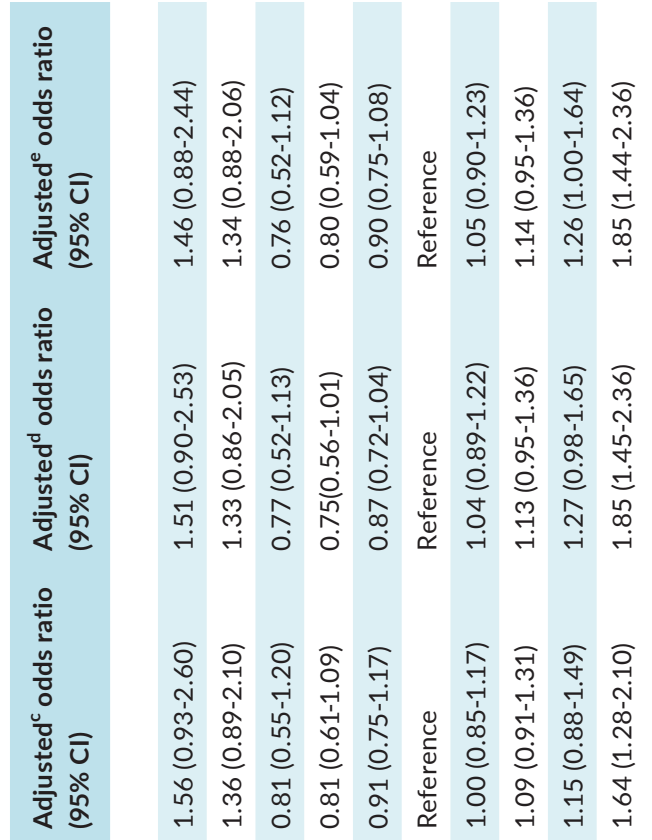

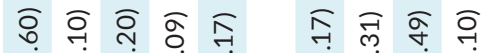

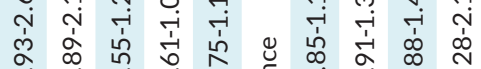

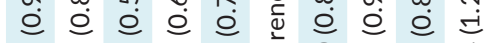
ڤొ

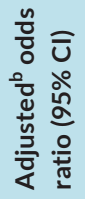

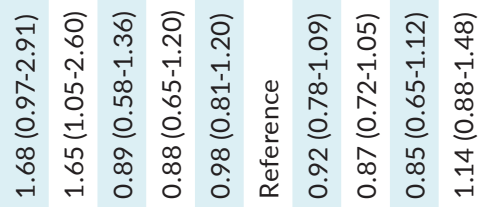

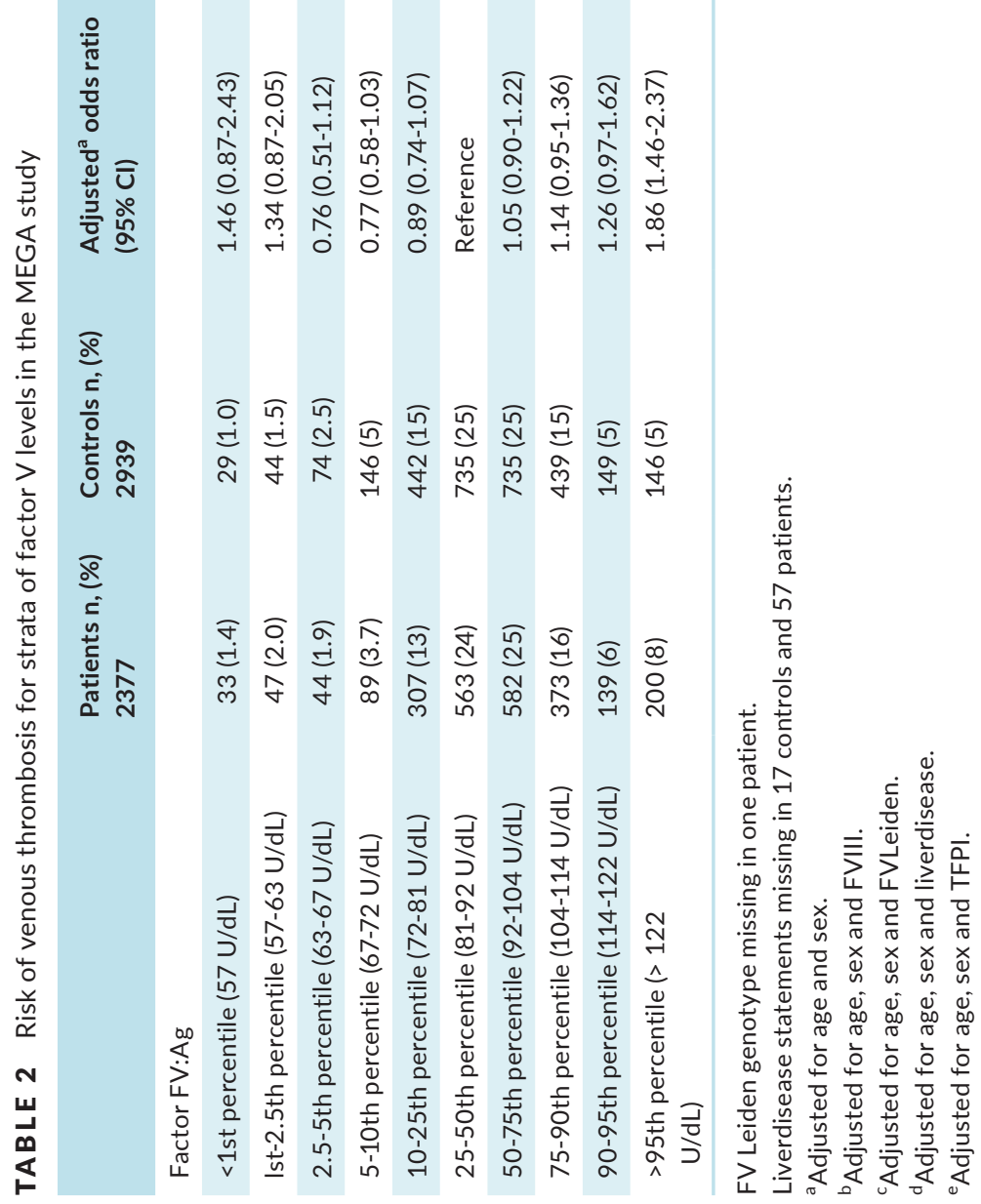


the two SNPs rs6033 proxy by rs1800595 and rs9332701 were associated with FV levels (Table 3 ), corroborating previous findings. ${ }^{23}$ The rs1800595-CC and rs9332701-CC genotypes were associated with the lowest levels of FV (75 and $79 \mathrm{U} / \mathrm{dL}$, respectively), with increasing levels for the CT genotype (mean difference of $8.3 \mathrm{U} / \mathrm{dL}$ for rs1800595-CT and $7.7 \mathrm{U} / \mathrm{dL}$ for rs9332701-CT) and the highest levels for the TT genotype (mean difference of $18.0 \mathrm{U} / \mathrm{dL}$ for rs1800595-TT and $13.6 \mathrm{U} / \mathrm{dL}$ for rs9332701-TT).

In an analysis including only patients from the MEGA study with unprovoked $\mathrm{VT}$, the risk estimate for high levels of $\mathrm{FV}$ did not change (>95th percentile; OR 1.78; 95\% Cl 1.24-2.57, Table 4), but the risk estimates for low levels of FV increased ( $<1$ st percentile; OR 2.64; $95 \% \mathrm{Cl}$ 1.23-5.64). After adjustment for FVIII levels the OR for high

TAB LE 3 Factor $V$ levels specified for genetic factors associated with factor $V$ levels in the MEGA study

\begin{tabular}{|c|c|c|c|}
\hline FV Leiden & GG & AG & AA \\
\hline Controls, $\mathrm{n}$ & 2795 & 138 & 6 \\
\hline $\mathrm{FV}: \mathrm{Ag} \mathrm{U} / \mathrm{dL}$ (SD) & $92(16)$ & $98(15)$ & $104(18)$ \\
\hline $\begin{array}{l}\text { Mean } \\
\text { difference } \\
(95 \% \mathrm{Cl})\end{array}$ & Reference & $6.2(3.5-9.0)$ & $12.2(-0.7-25.1)$ \\
\hline rs9332701 & $\mathrm{CC}$ & $\mathrm{CT}$ & TT \\
\hline Controls, $\mathrm{n}$ & 6 & 188 & 1616 \\
\hline $\mathrm{FV}: \mathrm{Ag} \mathrm{U} / \mathrm{dL}$ (SD) & 79 (10) & $87(15)$ & $93(16)$ \\
\hline $\begin{array}{l}\text { Mean } \\
\text { difference } \\
(95 \% \mathrm{Cl})\end{array}$ & Reference & $7.7(-2.3-17.7)$ & $13.6(3.3-23.6)$ \\
\hline rsl8005995 & $\mathrm{CC}$ & $\mathrm{CT}$ & TT \\
\hline Controls, $\mathrm{n}$ & 7 & 295 & 2595 \\
\hline $\mathrm{FV}: \mathrm{Ag} \mathrm{U} / \mathrm{dL}$ (SD) & $75(10)$ & $84(15)$ & $93(16)$ \\
\hline $\begin{array}{l}\text { Mean } \\
\text { difference } \\
(95 \% \mathrm{Cl})\end{array}$ & Reference & $8.3(-1.1-17.8)$ & $18(8.6-27.4)$ \\
\hline
\end{tabular}

levels decreased to 1.40 ( $95 \% \mathrm{Cl} 0.95-2.07)$, while the risk estimates for low FV levels did not change (<1st percentile; OR 2.51; $95 \% \mathrm{Cl}$ 1.11-5.68 and 1st-2.5th percentile; OR 2.01; 95\% Cl 0.95-4.29).

A replication of the risk analysis in the LETS, a smaller casecontrol study on VT risk, showed an association, except for the lowest group (<2.5th percentile; <77 U/dL: OR 0.86; 95\% Cl 0.35-2.12), where no association was found. In the group above an increased risk was found (2.5-5th percentile; 77-85 U/dL: OR 1.52 (0.69-3.37), although not significant. High levels of FV were associated with a slightly increased risk for VT (95th percentile; <187 U/dL; OR 1.89; $95 \% \mathrm{Cl} 1.06-3.38$ ) as compared to the reference group (25-50th percentile; 110-128 U/dL, Table 5).

\section{DISCUSSION}

While of most procoagulant factors only high levels are associated with an increased risk of VT, FV has both a procoagulant and an anticoagulant function and, therefore, a less predictable role in VT risk. Due to the large size of the current study population, it was possible to examine both the high and low extremes of the FV levels (>95th percentile and $\leq 1$ st percentile, respectively). We observed an association between high FV levels and VT (>95th percentile; >1.22 U/dL; OR 1.86; 95\% Cl 1.46-2.37, Table 2). Adjustment for liver disease did not affect the ORs and neither did FV Leiden, although levels of FV itself were slightly affected by the FV Leiden genotype, which was in accordance with a previous study ${ }^{15}$ In contrast, adjustment for FVIII levels reduced the risk estimates to unity for high levels of FV. Similar results were found in the LETS study (Table 5). This suggests that the association between high levels of FV and VT is not a causative relation but may be linked to concurrently high levels of FVIII.

Interestingly, low levels of FV were also found to associate with an increased risk for VT (<1st percentile; $\leq 57 \mathrm{U} / \mathrm{dL}$; OR 1.46; $95 \%$ $\mathrm{Cl}$ 0.87-2.43, Table 2). Adjustment for FVIII levels, which led to the

TA B LE 4 Risk of venous thrombosis for strata of clotting factor levels for unprovoked VT in the MEGA study

\begin{tabular}{|c|c|c|c|c|}
\hline & $\begin{array}{l}\text { Patients n, (\%) } \\
660\end{array}$ & $\begin{array}{l}\text { Controls n, (\%) } \\
2939\end{array}$ & $\begin{array}{l}\text { Adjusted }{ }^{\mathrm{a}} \text { odds } \\
\text { ratio }(95 \% \mathrm{Cl})\end{array}$ & $\begin{array}{l}\text { Adjusted }{ }^{\mathrm{b}} \text { odds } \\
\text { ratio }(95 \% \mathrm{Cl})\end{array}$ \\
\hline \multicolumn{5}{|l|}{ Factor FV:Ag } \\
\hline Ist-2.5th percentile (57-63 U/dL) & $11(1.7)$ & $44(1.5)$ & $1.91(0.93-3.90)$ & $2.01(0.95-4.29)$ \\
\hline 2.5-5th percentile $(63-67 \mathrm{U} / \mathrm{dL})$ & $10(1.5)$ & $74(2.5)$ & $0.86(0.42-1.73)$ & $0.79(0.37-1.68)$ \\
\hline 10-25th percentile (72-81 U/dL) & $67(10)$ & $442(15)$ & $0.84(0.61-1.16)$ & $0.82(0.58-1.16)$ \\
\hline 25-50th percentile (81-92 U/dL) & $141(21)$ & $735(25)$ & Reference & Reference \\
\hline 50-75th percentile (92-104 U/dL) & $161(24)$ & $735(25)$ & $1.07(0.83-1.38)$ & $0.97(0.74-1.27)$ \\
\hline 75-90th percentile (104-114 U/dL) & $119(18)$ & $439(15)$ & $1.21(0.91-1.60)$ & $1.06(0.78-1.43)$ \\
\hline 90-95th percentile (114-122 U/dL) & $53(8)$ & $149(5)$ & $1.56(1.07-2.27)$ & $1.18(0.79-1.78)$ \\
\hline
\end{tabular}

${ }^{a}$ Adjusted for age and sex.

${ }^{\mathrm{b}}$ Adjusted for age, sex and FVIII. 
TA B LE 5 Risk of venous thrombosis for strata of clotting factor levels in the LETS

\begin{tabular}{|c|c|c|c|c|c|c|}
\hline & $\begin{array}{l}\text { Patients n, (\%) } \\
474\end{array}$ & $\begin{array}{l}\text { Controls n, (\%) } \\
474\end{array}$ & $\begin{array}{l}\text { Adjusted }{ }^{\mathrm{a}} \text { odds } \\
\text { ratio }(95 \% \mathrm{Cl})\end{array}$ & $\begin{array}{l}\text { Adjusted }{ }^{b} \text { odds } \\
\text { ratio }(95 \% \mathrm{Cl})\end{array}$ & $\begin{array}{l}\text { Adjusted }{ }^{\mathrm{c}} \text { odds } \\
\text { ratio }(95 \% \mathrm{Cl})\end{array}$ & $\begin{array}{l}\text { Adjusted }{ }^{d} \text { odds } \\
\text { ratio }(95 \% \mathrm{Cl})\end{array}$ \\
\hline \multicolumn{7}{|l|}{ Factor FV:Ag } \\
\hline$<2.5$ th percentile $(<77 \mathrm{U} / \mathrm{dL})$ & 9 (1.9) & $12(2.5)$ & $0.86(0.35-2.12)$ & $0.85(0.34-2.12)$ & $0.99(0.38-2.54)$ & $0.86(0.35-2.13)$ \\
\hline 2.5-5th percentile $(77-85 \mathrm{U} / \mathrm{dL})$ & $16(3.4)$ & $12(2.5)$ & $1.52(0.69-3.37)$ & $1.52(0.69-3.37)$ & $1.96(0.86-4.44)$ & $1.53(0.69-3.40)$ \\
\hline 5-10th percentile (85-94 U/dL) & $25(5.3)$ & $25(5.3)$ & $1.14(0.62-2.11)$ & $1.14(0.62-2.11)$ & $1.23(0.65-2.33)$ & $1.15(0.62-2.13)$ \\
\hline 10-25th percentile $(94-110 \mathrm{U} / \mathrm{dL})$ & $64(14)$ & $70(15)$ & $1.05(0.68-1.61)$ & $1.05(0.68-1.61)$ & $1.11(0.72-1.74)$ & $1.06(0.69-1.62)$ \\
\hline $25-50$ th percentile (110-128 U/dL) & $104(22)$ & $119(25)$ & Reference & Reference & Reference & Reference \\
\hline 50-75th percentile (128-148 U/dL) & $118(25)$ & $120(25)$ & $1.13(0.78-1.62)$ & $1.13(0.78-1.63)$ & $1.02(0.70-1.49)$ & $1.14(0.79-1.65)$ \\
\hline 75-90th percentile (148-170 U/dL) & $75(16)$ & $69(15)$ & $1.24(0.82-1.89)$ & $1.25(0.82-1.91)$ & $1.13(0.72-1.75)$ & $1.26(0.83-1.93)$ \\
\hline 90-95th percentile (170-187 U/dL) & $25(5.3)$ & $24(5.1)$ & $1.19(0.64-2.21)$ & $1.20(0.64-2.23)$ & $1.08(0.56-2.08)$ & $1.21(0.65-2.26)$ \\
\hline >95 percentile (>187 U/dL) & $38(8.0)$ & $23(4.9)$ & $1.89(1.06-3.38)$ & $1.90(1.05-3.41)$ & $1.52(0.82-2.82)$ & $1.87(1.03-3.37)$ \\
\hline
\end{tabular}

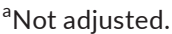

${ }^{\mathrm{b}}$ Adjusted for age, sex.

${ }^{\mathrm{c}}$ Adjusted for age, sex and FVIII.

${ }^{\mathrm{d}}$ Adjusted for age, sex and liver disease.

attenuation of the risk estimates for high levels of $\mathrm{FV}$, did not decrease the ORs here. Therefore, FVIII levels could not explain the association between low FV levels and VT. A possible explanation may be the role of inactivated $\mathrm{FV}$ as a cofactor in the inactivation of FVIII. ${ }^{12,13}$ Another possible pathway for the association between low FV levels and VT may involve TFPI. A patient study demonstrated that an isoform of FV, FV-short, can circulate bound to fulllength TFPI (TFPI $\alpha) .{ }^{17} \mathrm{~A}$ mutation of FV that increases the levels of FV-short, results in a bleeding phenotype by increasing the levels of TFPI $\alpha$. On the other hand, another study reported low TFPI levels in FV deficient individuals. ${ }^{18}$ These mechanisms might decrease the effectiveness of the anticoagulant pathway, which may lead to a potentially increased risk for VT. Here, we did not observe an effect when adjusting for total TFPI activity levels. However, different findings may be observed when specifically assessing the FV-short or TFPI $\alpha$ levels. An even stronger association between low FV levels and VT was found when the analysis was focused on unprovoked VT (<1st percentile; OR 2.64; 95\% Cl 1.23-5.64, Table 4). This suggests that low FV levels play a role in the risk for VT in individuals without a clinical risk factor for VT, and that the link is obscured in patients in whom a provoked risk factor was present. In the 474 cases and 474 controls from the LETS this result could not conclusively be confirmed, due to the lower number of participants, but the overall risk distribution appeared to be the same, with the exception of the lowest FV group (<2.5th percentile). Furthermore, different assays were used to determine FV levels: single chain FV was detected in the MEGA study, while FV light chain was measured in the LETS, which represents not only single chain FV, but also light chain fragments resulting from incomplete synthesis or proteolytic degradation such as by activated protein $\mathrm{C}^{15}$ The latter might explain the higher levels of FV observed in the LETS relative to those from the MEGA study. Moreover, this putative overestimation of FV plasma levels may also obscure the risk association, particularly in strata with low FV levels. Consistent with our findings obtained from the MEGA study, Suehisa et al. previously reported an association between low levels of FV and VT in unprovoked VT patients in the Japanese population. ${ }^{14}$

The current study has several limitations. Since blood was sampled after the occurrence of VT, effects of the thrombotic event on the levels of the coagulation factors cannot be ruled out. Furthermore, the assay used in the MEGA study had an upper detection limit of $125 \mathrm{U} / \mathrm{dL}$, which precluded analysis of the risk associated with FV levels $>125 \mathrm{U} / \mathrm{dL}$. However, as all values above this level were considered together in one category, this should not have affected our results. Likewise, the assay did not take platelet FV into account. The importance of platelet FV is underscored by a study of Duckers et al., ${ }^{11}$ in which patients with undetectable plasma FV and mild bleeding symptoms demonstrated improved coagulation in a thrombin generation assay in platelet-rich plasma. Since we used plasma without platelets, we cannot rule out an additive or reductive effect of platelet FV.

In conclusion, we found high FV levels to be associated with an increased risk for VT, which was explained by concurrently raised FVIII levels. Low levels of FV were also associated with $\mathrm{VT}$, which was most pronounced in individuals with unprovoked VT. This association was not explained by FVIII or any of the other mechanisms we explored.

\section{RELATIONSHIP DISCLOSURE}

The authors declare no competing financial interests.

\section{AUTHOR CONTRIBUTIONS}

I.M.R. performed the statistical analyses, interpreted the data and wrote the manuscript; R.L.G. performed statistical analyses; M.H.A.B and W.M.L. interpreted the data and reviewed the manuscript; F.R.R. was responsible for the MEGA study; P.H.P. reviewed the manuscript; S.C.C. designed the analyses and reviewed the manuscript. 
ORCID

Ruifang Li-Gao (iD http://orcid.org/0000-0003-0650-1351

Suzanne C. Cannegieter (iD http://orcid.org/0000-0003-4707-2303

\section{REFERENCES}

1. Liao S, Woulfe T, Hyder S, Merriman E, Simpson D, Chunilal S. Incidence of venous thromboembolism in different ethnic groups: a regional direct comparison study. J Thromb Haemost. 2014;12:214-9.

2. Anderson FA Jr, Wheeler HB, Goldberg RJ, et al. A populationbased perspective of the hospital incidence and case-fatality rates of deep vein thrombosis and pulmonary embolism. The Worcester DVT Study. Arch Intern Med. 1991;151:933-8.

3. Poort SR, Rosendaal FR, Reitsma PH, Bertina RM. A common genetic variation in the 3 '-untranslated region of the prothrombin gene is associated with elevated plasma prothrombin levels and an increase in venous thrombosis. Blood. 1996;88:3698-703.

4. Tsai AW, Cushman M, Rosamond WD, et al. Coagulation factors, inflammation markers, and venous thromboembolism: the longitudinal investigation of thromboembolism etiology (LITE). Am J Med. 2002;113:636-42.

5. de Visser MC, Poort SR, Vos HL, Rosendaal FR, Bertina RM. Factor $\mathrm{X}$ levels, polymorphisms in the promoter region of factor $\mathrm{X}$, and the risk of venous thrombosis. Thromb Haemost. 2001;85:1011-7.

6. Folsom AR, Tang W, Roetker NS, Heckbert SR, Cushman M, Pankow JS. Prospective study of circulating factor $\mathrm{XI}$ and incident venous thromboembolism: the Longitudinal Investigation of Thromboembolism Etiology (LITE). Am J Hematol. 2015;90: 1047-51.

7. Cushman M, O'Meara ES, Folsom AR, Heckbert SR. Coagulation factors IX through XIII and the risk of future venous thrombosis: the Longitudinal Investigation of Thromboembolism Etiology. Blood. 2009;114:2878-83.

8. Koster T, Blann AD, Briët E, Vandenbroucke JP, Rosendaal FR. Role of clotting factor VIII in effect of von Willebrand factor on occurrence of deep-vein thrombosis. Lancet. 1995;345:152-5.

9. Bertina RM, Koeleman BP, Koster T, et al. Mutation in blood coagulation factor $\mathrm{V}$ associated with resistance to activated protein $\mathrm{C}$. Nature. 1994;369:64-7.

10. Huang JN, Koerper MA. Factor $\vee$ deficiency: a concise review. Haemophilia. 2008;14:1164-9.

11. Duckers C, Simioni P, Spiezia L, et al. Residual platelet factor $\mathrm{V}$ ensures thrombin generation in patients with severe congenital factor $\mathrm{V}$ deficiency and mild bleeding symptoms. Blood. 2010;115:879-86.

12. Shen $L$, Dahlbäck B. Factor $V$ and protein $S$ as synergistic cofactors to activated protein $\mathrm{C}$ in degradation of factor VIIla. J Biol Chem. 1994;269:18735-8.

13. Dahlbäck B, Hildebrand B. Inherited resistance to activated protein $C$ is corrected by anticoagulant cofactor activity found to be a property of factor V. Proc Natl Acad Sci U S A. 1994;91:1396-400.

14. Suehisa E, Kawasaki T, Toku M, Hidaka Y. Low level of factor $V$ is associated with development of deep-vein thrombosis in Japanese patients. Thromb Res. 2010;125:128-33.

15. Kamphuisen PW, Rosendaal FR, Eikenboom JC, Bos R, Bertina RM. Factor $V$ antigen levels and venous thrombosis: risk profile, interaction with factor $\mathrm{V}$ leiden, and relation with factor VIII antigen levels. Arterioscler Thromb Vasc Biol. 2000;20:1382-6.

16. Bernuau J, Rueff B, Benhamou JP. Fulminant and subfulminant liver failure: definitions and causes. Semin Liver Dis. 1986;6:97-106.

17. Vincent LM, Tran S, Livaja R, Bensend TA, Milewicz DM, Dahlbäck B. Coagulation factor V(A2440G) causes east Texas bleeding disorder via TFPlalpha. J Clin Invest. 2013;123:3777-87.

18. Duckers C, Simioni P, Spiezia L, et al. Low plasma levels of tissue factor pathway inhibitor in patients with congenital factor $V$ deficiency. Blood. 2008;112:3615-23.

19. Zakai NA, Lutsey PL, Folsom AR, Heckbert SR, Cushman M. Total tissue factor pathway inhibitor and venous thrombosis. The Longitudinal Investigation of Thromboembolism Etiology. Thromb Haemost. 2010;104:207-12.

20. Javanmard SH, Shahsavarzadeh T, Saadatnia M. Low levels of tissue factor pathway inhibitor increase the risk of cerebral venous thrombosis. Adv Biomed Res. 2015;4:6.

21. Van Stralen KJ, Rosendaal FR, Doggen CJ. Minor injuries as a risk factor for venous thrombosis. Arch Intern Med. 2008;168:21-6.

22. Guasch JF, Cannegieter S, Reitsma PH, van't Veer-Korthof ET, Bertina RM. Severe coagulation factor $\mathrm{V}$ deficiency caused by a 4 bp deletion in the factor $\mathrm{V}$ gene. $\mathrm{Br} J$ Haematol 1998;101:32-9.

23. Suhre K, Arnold M, Bhagwat AM, et al. Connecting genetic risk to disease end points through the human blood plasma proteome. Nature Commun. 2017;8:14357.

How to cite this article: Rietveld IM, Bos MHA, Lijfering $W M$, et al. Factor $V$ levels and risk of venous thrombosis: The MEGA case-control study. Res Pract Thromb Haemost. 2018;2:320-326. https://doi.org/10.1002/rth2.12091 